\title{
Digital Libraries and the Common Digital Space of Mathematical Knowledge
}

\author{
Alexander Elizarov 1[0000-0003-2546-6897], Evgeny Lipachev 2[0000-0001-7789-2332] \\ ${ }^{1,2}$ Institute of Information Technologies and Intelligent Systems, Kazan (Volga Region) \\ Federal University, Kremliovskaya ul., 35, Kazan, 420008, Russia \\ 1 amelizarov@gmail.com, ${ }^{2}$ elipachev@gmail.com
}

\begin{abstract}
We present the results of the development of a range of semantic services for the integrated management of electronic scientific collections. The goals of these developments are the formation of a unified digital space of mathematical knowledge, as well as information support for research activities in the field of mathematics and computer science. The digital collections we create and the semantic services we develop form the backbone of the Lobachevskii-DML digital math library. In implementing this study, we used approaches that are consistent with the widely discussed and accepted concepts of building the World Digital Mathematical Library (WDML).
\end{abstract}

Keywords': Digital scientific library, scientific information space, unified digital space of mathematical knowledge, digital mathematical library, digital mathematical library Lobachevskii-DML.

\section{Introduction}

Today it is generally accepted that the digitalization of knowledge and the movement of scientific communications into the network space not only changed the existing scientific infrastructure, but also set new tasks for knowledge management (see, for example, [1]).

As you know, a necessary element of any scientific research is the description of the relationship of new scientific results with those obtained earlier. In modern conditions, in order to fulfill this requirement, it is necessary to have a sufficient amount of scientific content on the Internet, both modern and already classic.

\footnotetext{
${ }^{1}$ CDSSK-2020: International Conference "Common Digital Space of Scientific Knowledge", November 10-12, 2020, Moscow, Russia

EMAIL: amelizarov@gmail.com (Alexander Elizarov); elipachev@gmail.com (Evgeny

Lipachev);

ORCID: 0000-0003-2546-6897 (Alexander Elizarov); 0000-0001-7789-2332 (Evgeny

Lipachev);

(c) (i) (C) 2021 Copyright for this paper by its authors. Use permitted under Creative Commons

License Attribution 4.0 International (CC BY 4.0)

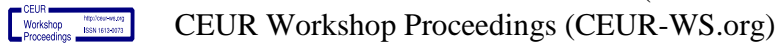


The digital era has fundamentally changed both the methods of research and the way scientists seek, produce scientific information, publish and disseminate the results of their scientific work. Currently, information and communication technologies (ICT) are being actively developed and implemented in research and development, which makes it possible to use the entire body of accumulated scientific knowledge when conducting new research. In turn, such use requires the creation of a complex of new technologies that provide optimal management of existing knowledge, the organization of effective access to them, as well as the exchange and reuse of new types of knowledge structures (see, for example, [2]).

To a certain extent, traditional libraries are solving the problem of moving from storing paper documents to managing digital content. Today they use networked tools in their work and thus have significantly expanded their standard functions. At the same time, the amount of information available in the world is so wide that in order to work effectively and successfully with it, it is necessary to develop constructive options for narrowing this set. In particular, as a variant of narrowing the set of available information, we can talk about the formation of a scientific information space, which itself is huge. Note that the concept of "information space" and its various aspects have been widely studied in the context of various fields of activity, both from theoretical and practical points of view [3-5]. In the broadest sense, the information space is the totality of the results of the semantic activity of mankind.

The methods of narrowing the scientific information space itself are: the specification of the processed information, limiting the circle of its users, as well as the development of a complex of software and hardware. These methods provide the use of scientific resources and full-featured management of them. Thus, a corresponding subspace of the scientific information space can be formed, and the restrictions mentioned above should more accurately specify information and ensure its integration. It is in this sense that we are talking about the Single digital space of mathematical knowledge, which will become part of the new specialized scientific digital infrastructure being formed.

\section{Digital libraries as part of a specialized scientific infrastructure}

One of the directions for the development and use of digital technologies in scientific activities provides for the organization at a modern level and using ICTs access to the latest scientific results, in particular, scientific publications and scientometric information about them. Historically, this direction is associated with the formation of digital libraries (Digital Library - DL) in the world, including scientific ones. Their active development began at the end of the 20th century. (see, for example, [6-9]).

In general, digital libraries of any orientation (not only scientific) are understood as models of complex information systems that serve as the basis for the creation of universal distributed repositories of knowledge and are equipped with navigation and search tools in collections of heterogeneous electronic documents that are included in these repositories [9]. 
Currently, digital libraries exist and are actively developing in all developed countries of the world. The largest international digital libraries are the scientometric databases Web of Science (until 2014 - Web of Knowledge) (https://clarivate.com/webofsciencegroup/solutions/web-of-science/) and Scopus (https: //www.scopus.com/).

So, at present, in the field of science and scientific research, a significant number of various digital scientific libraries have been formed. They are associated with modern publishing and scientometric services and implement a wide range of search services. Each of them has its own ecosystem.

Digital libraries play a huge role in accelerating the circulation and access to existing knowledge. But without the Internet, which has become today a comprehensive integrated information environment, extracting information from various kinds of information sources would be impossible. A variety of digital libraries are such sources. At the same time, a number of serious problems arise in ensuring the integration (coherence) of the extracted information. Therefore, narrowing the entire space of available information makes it possible to more accurately specify information and, therefore, provide better access to it and its use. Note that such a narrowing can be provided within the framework of specialized digital scientific libraries, which are organized in specific subject areas. For example, digital mathematical libraries (DML) have reached a high level of organization, performing various functions of integrating mathematical knowledge [10-14]. An overview of the specifics and functionality of a number of existing digital mathematical libraries is contained in [15].

\section{Digital Mathematical Libraries (DML)}

Today, thanks to the widespread introduction of digital technologies in research and development, it has become possible to use the entire body of accumulated scientific knowledge when conducting new research. Such use presupposes the creation of a set of technologies that ensure optimal management of existing knowledge, the organization of effective access to them, as well as the joint and repeated use of new types of knowledge structures.

The greatest effect from the introduction of digital technologies for the further organization of scientific knowledge and improvement of their understanding is expected in the field of mathematics, where, as noted above, a significant number of digital libraries have already been created. These expectations are fully supported by the idea of creating the World Digital Mathematical Library (WDML). The main goal of WDML is to combine digitized versions of the entire array of scientific mathematical documents into a distributed system of interconnected repositories, including both modern sources and those that have already become historical.

The term WDML was introduced in 2006 at the General Assembly of the International Mathematical Union (see [16-18]). In 2012, at the Future World Heritage Digital Mathematical Library Symposium at the American National Academy of Sciences (see URL: $\quad$ http://ada00.math.uni-bielefeld.de/mediawiki-1.18.1/index.php/Main_Page; URL: $\quad$ http://ada00.math.uni-bielefeld.de/mediawiki- 
1.18.1/index.php/Final_report_draft) and in 2014 within the framework of the International Mathematical Congress (Seoul, South Korea) $[19,20]$ meetings of expert groups from participants with around the world to discuss practical action plans for the creation of the Global Digital Mathematical Library (GDML). In 2014, the report "Development of the global library of mathematical research in the 21 st century" [21] was prepared, in which the main tasks of building WDML were formulated. Thus, the main tasks of constructing WDML and the technologies required to solve them were discussed in 2014-2015 by a wide range of mathematicians. They are enshrined in a number of documents adopted by the World Mathematical Union. In particular, it was approved that the next steps in advancing mathematics would be to go beyond traditional mathematical publications and create a network of information based on the knowledge contained in these publications. Through a combination of machine learning techniques and the efforts of the editorial boards and editorial boards of mathematical scientific journals, much of the information and knowledge (in the form of connected open data) in the global body of mathematical knowledge will be made available to researchers through WDML.

At the same time, scientists increasingly need new ways to discover objects of scientific knowledge directly via the Internet, as well as tools and services that ensure the creation and sharing of new types of knowledge structures. In the context of the concept of linked data and the semantic web, such tools and services can be used to create "collaboration charts" that are useful, for example, to calculate "collaboration distance" between authors and highlight "similar" documents (see [22-24]). This opens up new possibilities for fine-tuning search and browsing (see, for example, [25, 26]). Many authors (for example, [27-32]) emphasize the importance of developing new ontologies of subject areas, in particular, mathematics, since traditional bibliographic cataloging is no longer enough today; more detailed elaboration is required, containing descriptions created from different points of view. All of the above is aimed at the formation of a unified digital space of mathematical knowledge.

\section{Mathematical scientific heritage: digitization and accessibility}

The problems of integrating the knowledge gained in the field of mathematics over the entire "printed" period of the development of this science were considered in a number of projects. Even if these projects were local in nature, the methods and tools developed during their implementation were focused on the comprehensive integration of mathematical knowledge (see, for example, [1]), and the achieved level of development made it possible to raise the issue of creating WDML.

One of the policy documents [21] of a project aimed at creating WDML contains the phrase "Like most areas of scholarship, mathematics is a cumulative discipline". $\mathrm{Cu}$ mulativeness in this context means that new research in mathematics is always based on carefully selected literature that reflects well the background of the research. Moreover, the named document provides a comparison of mathematics with art. This comparison is based on the fact that the primary data that mathematicians encounter in their research are human creations, and not data obtained as a result of physical observations 
of our universe or measurements. Therefore, all mathematical information that exists today and is used in new mathematical research is actually extracted from the existing mathematical literature or calculated. It is also known that in modern mathematical research the number of references to documents published in the "pre-digital" period does not decrease at all. In addition, in works reflecting the activities of many research groups actively involved in the integration of mathematical knowledge (see, for example, [32-36]), it is noted that both mathematical results obtained earlier and the systems of reasoning and proofs associated with them, must be preserved and accessible through modern effective means of scientific communication. Digital math libraries are one such tool. The current vision of the tasks of forming a global infrastructure of mathematical knowledge is formalized in the documents of the WDML project (for example, [21]). At the same time, it was noted that the leading role in the formation of electronic mathematical collections, creation of verification methods, metadata support, annotation, etc. is assigned to the "smaller" DML. A comparison of a number of such DMLs, as noted above, is contained in [15]. Now let's dwell on the results of the digitization of mathematical sources by the time the WDML project was launched.

As noted in [21], today a very significant part of the mathematical literature of the 20 th century is available in digital form. In addition, thanks to projects such as the Jahrbuch Electronic Research Archive for Mathematics (http://www.emis.de/projects/JFM/), as well as the independent efforts of many publishers and researchers, many important results of mathematical research in the second half of the 19th century have been digitized. Access to this information is possible partly freely, partly by subscription.

Also, a significant part of the historical mathematical literature has been digitized since the beginning of the 21 st century. The most comprehensive list of retro-digitized mathematical literature today, as in 2014, is Ulf Rehmann's list of retro-digitized mathematical journals and monographs in DML (http://www.mathematik.uni-bielefeld.de/ rehmann/DML/dml_links. html). However, this list does not include the metadata that has ended up in indexes maintained by Google, the American Mathematical Society (MathSciNet, http://www.ams.org/mathscinet/) and Zentralblatt (zbMATH, http://zbmath.org/).

Today the digital corpus of mathematical literature is quite extensive. According to [21], at the time of 2014, the MathSciNet database included about 2.9 million publications, starting from 1940, with direct links to 1.7 million of them. DML MathSciNet also indexed more than 2 thousand titles of magazines (as well as serials) and contained about 100 thousand books (published after 1960). There were 2.6 million available sources on MathSciNet since 1970 and 1.7 million since 1990. The zbMATH database contained more than 3 million publications and indexed about 3.5 thousand journals since 1931.

In the following years, the components of the digitized corpus of mathematical editions were increasingly incorporated into stable and well-formed repositories, although access to much of the corpus remained restricted by copyright or other intellectual restrictions on access rights. 


\section{$5 \quad$ "Smaller" DMLs and their features}

In addition to the large projects mentioned above, the digitization of the mathematical scientific heritage and the provision of access to it were implemented in a large number of different projects and were based on the creation of modern national digital mathematical libraries. Most of these projects were started in the first decade of the 21 st century. Some of them have been completed by now, their active operation has ended.

Most of the existing digital mathematical libraries are built as national ones. For this reason, these DMLs have specific features both in architecture and in the scientific content management technologies they use. Earlier in [15], we compared these national DMLs for the technologies used. Some of the more notable of these DMLs are:

$\checkmark$ All-Russian Mathematical Portal Math-Net.Ru

(URL:http://www.mathnet.ru/);

$\checkmark \quad$ Bulgarian Digital Mathematics Library

(URL: http://sci-gems.math.bas.bg/jspui/);

$\checkmark$ CEDRAM (URL: www.cedram.org);

$\checkmark$ Czech Digital Mathematics Library (DML-CZ) (URL: http://www.dml.cz/);

$\checkmark$ European Digital Mathematics Library EuDML (URL: www.eudml.org);

$\checkmark$ Gallica (URL: https://gallica.bnf.fr);

$\checkmark$ Gottingen DigitalisierungsZentrum (http://gdz.sub.uni-goettingen.de/gdz/);

$\checkmark \quad$ JSTOR (URL: https://www.jstor.org/);

$\checkmark$ Lobachevskii-DML (URL: http://www.lobachevskii-dml.ru/);

$\checkmark$ NUMDAM (URL: www.numdam.org);

$\checkmark \quad$ Polish Digital Mathematics Library (URL: http://pldml.icm.edu.pl/);

$\checkmark$ RusDML (Russian Digital Mathematics Library, URL: https://www.sub.unigoettingen.de/projekte-forschung/projektdetails/projekt/rusdml/).

The all-Russian portal Math-Net.Ru (URL: http://www.mathnet.ru/) is a modern digital library that provides Russian and foreign scientists with various opportunities to search for scientific information on mathematics, physics, information technology and related sciences in Russian. This project has been developing since 2006 (see [37-39]). This digital library today contains more than 293 thousand publications (including more than 276 thousand scientific articles) from 143 scientific journals; more than 24.7 thousand reports and lectures presented at 1755 conferences. For example, the issues of the journal "Mathematical Collection" are presented in the named digital library since 1866 - since the publication of the first issue of this journal.

Projects "Center de diffusion de revues académiques mathématiques" (CEDRAM, URL: http://www.cedram.org/), Numerisation de Documents Anciens Mathematiques (NUMDAM, URL: http://www.numdam.org/) and Gallica (URL: https: //gallica.bnf.fr) form the basis of the French digital ecosystem of access to documents in French, including mathematical ones, both archival and only then digitized, and created immediately in digital format (see $[40,41])$.

Note that the first two of these digital libraries contain only mathematical documents. According to the latest information, the French digital mathematical library NUMDAM 
contains almost 60 thousand articles from 76 periodicals, 698 books and 5 collections, as well as 263 dissertations (in total, more than 1 million pages for reading in free access). The Gallica digital library contains mathematical content only along with information from other subject areas.

The European Digital Mathematical Library EuDML is a project funded by the European Commission in 2010-2013. Together with 13 partners from 9 European countries, a digital library formation service was developed to provide online access to mathematical literature (see [42, 43]).

The main goal of local projects, united by the above-mentioned activities, was to create a common infrastructure of digital mathematical libraries, providing access to mathematical knowledge concentrated in local collections of scientific journals, collections and books. These were, for example, the projects Bulgarian Digital Mathematical Library (BulDML) and Czech Digital Mathematics Library (DML-CZ, completed in 2009) [44]. Today the Polish Digital Mathematics Library project is not actively functioning within the EuDML framework.

The RusDML project (Russian Digital Mathematics Library, URL: https://www.sub.uni-goettingen.de/projekte-forschung/projektdetails/projekt/rusdml/) was implemented within the framework of German-Russian cooperation (completed in 2007) [45]. It is part of a global program to provide mathematicians around the world with digital access to all mathematical literature. The first stage of this project was the digitization of the most important Russian-language journals since 1866. This information is available online using the Zentralblatt MATH as a portal. The RusDML project, which was supported by the DFG (Deutsche Forschungsgemeinschaft), involved three German partners: the Technical University of Berlin, the State University Library of Göttingen and the Hannover Technical Information Library. The Russian partner is the State Public Scientific and Technical Library in Moscow.

The Göttingen Retrospective Digitization Center (Göttingen DigitalisierungsZentrum, GDZ) was founded in 1997 and is currently implementing a retrospective library digitization program as part of an initiative to develop a digital research library in Germany. The created specialized information service for mathematics (URL: https://gdz.sub.uni-goettingen.de/collection/fid.mathematica) allows access to many mathematical sources of information from one point.

The JSTOR Digital Library was created in 1995 following a pilot project from the University of Michigan as an independent non-profit organization. Today it contains digitized collections not only in mathematics, but also in various fields of knowledge. The volume of this resource is more than 12 million articles of academic journals and books in 75 disciplines. In physics and mathematics, the oldest documents in this digital library are digitized editions of the 15 th to 16 th centuries.

So, scientific digital libraries as a specialized class of information systems are the most important component of any scientific information space, and the construction of such libraries is directly aimed at integrating knowledge and expanding access to it. The foregoing is fully reflected in the main tasks set in projects that are related to the development of digital mathematical libraries, are partially described above and perform the functions of integrating mathematical knowledge. Many of the existing DMLs are built as national ones and, for this reason, have peculiarities both in architecture and 
in the technologies for managing scientific content that they use. These features must be studied and taken into account. Along with the construction of various DMLs, a number of new issues have arisen related to the development of digital library technologies.

We faced such questions when creating a digital mathematical library Lobachevskii Digital Mathematics Library (Lobachevskii-DML, http://www.lobachevskii-dml.ru/) $[46,47]$. It is developed by us in accordance with the basic principles of WDML. Its task is to develop tools for managing mathematical content that take into account not only the specifics of mathematical texts, but also the peculiarities of processing Russian-language texts. The particular task of creating this digital library was the integration of the mathematical resources of Kazan University, which explains the choice of its name. In addition, the project for the creation of Lobachevskii-DML started in the year of the 225th anniversary of the birth of the brilliant mathematician Nikolai Ivanovich Lobachevskii, the founder of non-Euclidean geometry, graduate and rector of Kazan University from 1827 to 1845 ; this year was the year of the beginning of the construction of Lobachevskii-DML.

One of the basic directions of research developed within the framework of this digital mathematical library is associated with the development of a system of interconnected software tools that ensure the creation, processing, storage, management of metadata of digital library objects and the integration of created electronic collections into digital scientific libraries that aggregate them. We call the system of such tools a metadata factory $[48,49]$.

\section{DML metadata factory}

The creation of any digital mathematical library and the subsequent expansion of its functionality presupposes the solution of a number of time-consuming tasks associated, first of all, with content management. That is why scientific content management software tools are an essential component of any digital library. Many of these tools are used by the metadata factory to create, process, store and manage the metadata of digital documents and allow the creation of digital collections to be integrated into aggregating digital scientific libraries. Let's describe in more detail the available solutions.

Existing digital libraries, as well as aggregators of scientific knowledge, offer a number of software tools for working with content, primarily search services in digital collections. For example, semantic document search tools are available on the EuDML project site (URL: https://initiative.eudml.org/). It also contains demos of tools developed to serve EuDML. The purpose and functionality of these software tools are described in [50].

To optimize the named tools of the metadata factory and their subsequent modernization, it was necessary:

$\checkmark \quad$ to identify and describe the peculiarities of the presentation of metadata of documents of various electronic collections associated with both the formats used and with changes in the composition and completeness of the set of 
metadata during the entire existence of the corresponding scientific publication;

$\checkmark \quad$ to characterize software tools for scientific content management and methods of organizing automated integration of repositories of mathematical documents with other information systems;

$\checkmark \quad$ to characterize software tools for scientific content management and methods of organizing automated integration of repositories of mathematical documents with other information systems;

As a result, the developed tools of the metadata factory of the digital mathematical library Lobachevskii-DML became (see [48]):

$>$ a system of services for the automated generation of metadata for electronic mathematical collections;

$>$ xml-language for metadata representation, based on the Journal Archiving and Interchange Tag Suite (NISO JATS) of various versions [51];

$>$ created software tools for normalizing metadata of electronic collections of scientific documents in formats developed by aggregators of resources in mathematics and Computer Science;

$>\quad$ an algorithm for converting metadata to the oai_dc format and generating the structure of archives for import into the digital storage DSpace;

$>$ methods of integration of existing electronic mathematical collections of Kazan University into domestic and foreign digital mathematical libraries [5256].

As in the case of any digital scientific library, the formation of Lobachevskii-DML and the corresponding metadata factory required the involvement of previously created ones, as well as the development of new technological solutions for scientific content management.

A number of digital math library metadata factory tools are designed to perform metadata harmonization and normalization procedures.

Harmonization of metadata implies the possibility of the simultaneous use of several different metadata standards in one software system. Metadata normalization methods are used to map several different metadata standards into a single schema or structure for further use in a single software system (see, for example, [56-58]).

Tasks related to the normalization of metadata in various formats are one of the most relevant when working with a metadata factory. Examples of such tasks are: normalization to formats for internal storage and loading into a digital library; normalization in formats of other digital libraries and aggregators or presentation in the form of bibliographic citation formats.

The Lobachevskii DML digital library implements several services that normalize metadata to various formats. So, one of them is the service for converting the metadata of the electronic collection of articles of the "Russian Digital Libraries Journal" (https://elbib.kpfu.ru/) into the DBLP database format (URL: https: //dblp.uni-trier.de/). 
The developed metadata transformation algorithm includes semantic transliteration of the names and surnames of the authors of the articles. The initial sets of metadata used in the conversion to the named format were generated automatically using the software tools developed by us, taking into account the specifics of the Open Journal Systems software platform [59] on which this journal operates. The algorithm for translating this metadata into the DBLP format has been successfully implemented; it is described in detail in $[48,56]$.

Our research, the results of which are presented above, is consistent with the ideology of the WDML project and will help, in our opinion, to move forward in solving the problems posed by this project.

\section{Conclusion}

The directions of development and use of digital technologies in scientific activities based on digital libraries were discussed. The role of digital mathematical libraries in the formation of a single digital space of mathematical knowledge is described. The concept of a metadata factory is introduced as a system of interconnected software tools aimed at creating, processing, storing and managing metadata of digital library objects and allowing to integrate the created digital collections into aggregating digital scientific libraries. A number of tasks related to the construction of a metadata factory for the digital mathematical library Lobachevskii-DML have been solved. It is proposed to use this implemented metadata factory as a component of any scientific digital library.

This work was financially supported by the Russian Science Foundation (project No. 21-11-00105).

\section{References}

1. Borwein, J.M., Rocha, E.M., Rodrigues, J.F. (Ed.): Communicating Mathematics in the Digital Era, A K Peters, Ltd., CRC Press, 325 p. (2008).

2. Carette, J., Farmer, W.M., Kohlhase, M., Rabe, F.: Big Math and the One-Brain Barrier: The Tetrapod Model of Mathematical Knowledge 43. P. 78-87 (2021). https://doi.org/10.1007/s00283-020-10006-0.

3. Ataeva, O., Kalenov, N., Serebryakov, V.: Ontological Approach to the Description of a Common Digital Space of Scientific Knowledge. In: CEUR Workshop Proceedings 2784. P. 295-303 (2020). URL: http://ceur-ws.org/Vol-2784/spaper01.pdf, last accessed $2021 / 07 / 24$

4. Kalenov, N.E., Savin, G.I, Sotnikov, A.N.: The Architecture of the Common Digital Space of Scientific Knowledge. In: N. E. Kalenov, A. N. Sotnikov (Ed.): Edinoe cifrovoe prostranstvo nauchnyh znanij: problemy i resheniya: sbornik nauchnyh trudov. Direktmedia Pablishing. P. 7-16. Moscow, Berlin (2021). https://doi.org/10.23681/610687

5. Ataeva, O.M., Kalenov, N.E., Serebryakov, V.A, Sotnikov A.N.: Functionality of a Common Digital Space of Scientific Knowledge. In: N.E. Kalenov, A.N. Sotnikov (Ed.), Edinoe cifrovoe prostranstvo nauchnyh znanij: problemy i resheniya: sbornik nauchnyh trudov, Direktmedia Pablishing. P. 89-107. Moscow, Berlin (2021).

https://doi.org/10.23681/610687 
6. Arms, W.Y.: Digital Libraries. MIT Press, Cambridge, MA, London, 287 p. (2000).

7. Lesk, M.: Understanding Digital Library, 2nd. ed. Elsevier Inc., 456 p. (2005).

8. Antopol'skij, A.B, Majstrovich, T.V.: Elektronnye biblioteki: principy sozdaniya. LiberiaBibinform, Moscow, 288 p. (2007).

9. Xie, I., Matusiak, K.K.: Discover Digital Libraries: Theory and Practice. Elsevier Inc., 388 p. (2016).

10. Jackson, A.: The Digital Mathematics Library. Notices Amer. Math. Soc. 50. P. 918-923 (2003).

11. Bouche, T.: Introducing the mini-DML project. In: ECM4 Satellite Conference EMANI/DML, P. 19-29 (2004).

12. Bouche, T.: Some Thoughts on the Near-Future Digital Mathematics Library. In: P. Sojka (Ed.): DML 2008, Towards a Digital Mathematics Library, Masaryk University, P. 3-15 (2008).

13. Bouche, T.: Digital Mathematics Libraries: The Good, the Bad, the Ugly. Math. Comput. Sci. 3. P. 227-241 (2010). https://doi.org/10.1007/s11786-010-0029-2

14. Bouche, T.: The Digital Mathematics Library as of 2014. Notices Amer. Math. Soc. 61 (9). P. 1085-1088 (2014). http://dx.doi.org/10.1090/noti1162

15. Elizarov, A.M., Lipachev, E.K., Zuev, D.S.: Digital Mathematical Libraries: Overview of Implementations and Content Management Services. In: CEUR Workshop Proceedings 2022. P. 317-325 (2017). URL: http://ceur-ws.org/Vol-2022/paper49.pdf, last accessed 2021/07/24.

16. The Digital Mathematical Library Project. Status August 2005. URL: http://www.math.uiuc.edu/ tondeur/DML04.pdf, last accessed 2021/07/24.

17. Digital Mathematics Library: a Vision for the Future. International Mathematical Union, 2006. URL: http://www.mathunion.org/fileadmin/IMU/Report/dml_vision.pdf, last accessed 2021/07/24.

18. Tondeur, P.: WDML: The World Digital Mathematics Library. The Evolution of Mathematical Communication in the Age of Digital Libraries. In: IMA Workshop, December 8-9, 2006. URL: http://www.math.uiuc.edu/ tondeur/WDML_IMA_DEC2006.pdf, last accessed 2021/07/24.

19. Olver, P.J.: The World Digital Mathematics Library: Report of a Panel Discussion. In: Proceedings of the International Congress of Mathematicians, August 13-21, 2014, Seoul, Korea. Kyung Moon SA, 2014, Vol. 1. P. 773-785 (2014).

20. Pitman, J., Lynch, C.: Planning a 21st Century Global Library for Mathematics Research. Notices of the AMS 61 (7). P. 776-777 (2014). http://dx.doi.org/10.1090/noti1143

21. Developing a 21st Century Global Library for Mathematics Research, DC: The National Academies Press, Washington. https://doi.org/10.17226/18619

22. Elizarov, A.M., Kirillovich, A.V., Lipachev, E.K., Zhizhchenko, A.B, Zhil'tsov, N.G.: Mathematical Knowledge Ontologies and Recommender Systems for Collections of Documents in Physics and Mathematics. Doklady Mathematics 93 (2). P. 231-233 (2016). https://doi.org/10.1134/S1064562416020174

23. Pechnikov, A.: Properties of Communication Graph of Academic Web. In: CEUR Workshop Proceedings 2543. P. 414-421 (2020). URL: http://ceur-ws.org/Vol-2543/spaper13.pdf, last accessed 2021/07/24.

24. Pechnikov, A., Chebukov, D., Nwohiri, A.: Communication of Scientists Through Scientific Publications: Math-Net.Ru as a Case Study. In: CEUR Workshop Proceedings 2784. P. 234 244 (2020). URL: http://ceur-ws.org/Vol-2784/rpaper19.pdf 
25. Beskaravaynaya, E.V., Dovbnya, E.V., Zakharova, S.S.: Problemno-orientirovannye kollektsii. Formirovanie i analiz na primere bazy dannykh trudov sotrudnikov Instituta biofiziki kletki. Bibliografiya 4. S. 30-36 (2008). last accessed 2021/07/24.

26. Todeschini, R., Baccini, A.: Handbook of Bibliometric Indicators: Quantitative Tools for Studying and Evaluating Research. Wiley-VCH Verlag (2016). https://doi.org/10.1002/9783527681969

27. Elizarov, A., Kirillovich, A., Lipachev, E., Nevzorova, O.: Semantic Formula Search in Digital Mathematical Libraries. In: Proceedings of the 2nd Russia and Pacific Conference on Computer Technology and Applications (RPC 2017). IEEE. P. 39-43 (2017). https://doi.org/10.1109/RPC.2017.8168063.

28. Lange, Ch.: Ontologies and Languages for Representing Mathematical Knowledge on the Semantic Web. Semantic Web Journal 4 (2). P. 119-158 (2013). URL: http://www.semantic-web-journal.net/sites/default/files/swj122.pdf, last accessed 2021/07/24.

29. Elizarov, A., Kirillovich, A., Lipachev, E., Nevzorova, O., Solovyev, V., Zhiltsov, N.: Mathematical Knowledge Representation: Semantic Models and Formalisms. Lobachevskii J. of Mathematics 35 (4). P. 347-353 (2014). https://doi.org/10.1134/S1995080214040143

30. Elizarov, A.M., Kirilovich, A.V., Lipachev, E.K, Nevzorova, O.A.: Mathematical Knowledge Management: Ontological Models and Digital Technology. In: CEUR Workshop Proceedings 1752. P. 44-50 (2016). URL: http://ceur-ws.org/Vol-1752/paper08.pdf, last accessed 2021/07/24.

31. Kirillovich, A., Nevzorova, O., Falileeva, M., Lipachev, E., Shakirova, L.: OntomathEdu: A Linguistically Grounded Educational Mathematical Ontology. In: C. Benzmüller, B. Miller (Ed.): Intelligent Computer Mathematics, CICM-2020, volume 12236 of Lecture Notes in Computer Science, Springer, Cham. P. 157-172 (2020). https://doi.org/10.1007/978-3-030-53518-6_10

32. Ataeva, O.M., Serebryakov, V.A., Tuchkova, N.P.: Knowledge Preservation and Development of Scientific Schools in the Digitalization Process. In: N.E. Kalenov, A.N. Sotnikov (Ed.): Edinoe cifrovoe prostranstvo nauchnyh znanij: problemy i resheniya : sbornik nauchnyh trudov, Direktmedia Pablishing, Moscow, Berlin. P. 427-450 (2021). https://doi.org/10.23681/610687

33. Rocha, E.M., Rodrigues, J.F.: Disseminating and Preserving Mathematical Knowledge. In: J.M. Borwein, E.M. Rocha, J.F. Rodrigues (Ed.): Communicating Mathematics in the Digital Era, A K Peters, Ltd. P. 3-21 (2008).

34. Ion, P.: The Effort to Realize a Global Digital Mathematics Library. In: G.M. Greuel, T. Koch, P. Paule, A. Sommese (Ed.): Mathematical Software - ICMS 2016, volume 9725 of Lecture Notes in Computer Science. Springer, Cham, P. 458-466 (2016). https://doi.org/10.1007/978-3-319-42432-3_59

35. Ion, P.D.F, Watt, S.M.: The Global Digital Mathematics Library and the International Mathematical Knowledge Trust. In: H. Geuvers, M. England, O. Hasan, F. Rabe, O. Teschke (Ed.): Intelligent Computer Mathematics - CICM 2017, volume 10383 of Lecture Notes in Computer Science, Springer, Cham. P. 56-69 (2017). https://doi.org/10.1007/978-3-319-62075-6_5.

36. Elizarov, A., Gafurova, P., Lipachev, E.: Metadata Extraction Methods for Organizing a Retro-Collection in the Lobachevskii Digital Mathematical Library. In: CEUR Workshop Proceedings 2784. P. 62-71 (2020). URL: http://ceur-ws.org/Vol-2784/rpaper06.pdf, last accessed 2021/07/24.

37. Zhizhchenko, A.B., Izaak, A.D.: The Information System Math-Net.Ru. Application of Contemporary Technologies in the Scientific Work of Mathematicians, Russian Math. Surveys 62 (5). P. 943-966 (2007). http://dx.doi.org/10.1070/RM2007v062n05ABEH004455. 
38. Zhizhchenko, A.B., Izaak, A.D.: The Information System Math-Net.Ru. Current State and Prospects. The Impact Factors of Russian Mathematics Journals, Russian Math. Surveys 64 (4). P. 775-784 (2009). http://dx.doi.org/10.1070/RM2009v064n04ABEH004638

39. Chebukov, D.E., Izaak, A.D., Misyurina, O.G., Pupyrev, Yu.A., Zhizhchenko, A.B.: MathNet.Ru as a Digital Archive of the Russian Mathematical Knowledge from the XIX Century to Today. In: CICM'13: Proceedings of the 2013 International Conference on Intelligent Computer Mathematics. July 2013. P. 344-348 (2013). https://doi.org/10.1007/978-3-642-39320-4_26

40. Bouche, T.: Toward a Digital Mathematics Library? A French Pedestrian Overview. In: J.M. Borwein, E.M. Rocha, J.F. Rodrigues (Ed.): Communicating Mathematics in the Digital Era, A K Peters, Ltd. P. 47-73 (2008).

41. Bouche, T., Labbe, O.: The New Numdam Platform. In: H. Geuvers, M. England, O. Hasan, F. Rabe, O. Teschke (Ed.), Intelligent Computer Mathematics - CICM 2017, volume 10383 of Lecture Notes in Computer Science, Springer, Cham. P. 70-82 (2017). https://doi.org/10.1007/978-3-319-62075-6_6. URL: https://zenodo.org/record/581405, last accessed 2021/07/24

42. Sylwestrzak, W., Borbinha, J., Bouche, T., Nowinski, A., Sojka, P.: EuDML - Towards the European Digital Mathematics Library. In: P. Sojka (Ed.): Towards a Digital Mathematics Library, Paris, July 7 - 8th 2010, Masaryk University Press, Brno. P. 11-26 (2010). URL: http://dml.cz/bitstream/handle/10338.dmlcz/702569/DML_003-2010-1_5.pdf, last accessed 2021/07/24.

43. Bouche, T.: Reviving the Free Public Scientific Library in the Digital Age? The EuDML Project. In: K. Kaiser, S. Krantz, B. Wegner (Ed.): Topics and Issues in Electronic Publishing, JMM, Special Session, San Diego. P. 57-80 (2013). URL: http://www.emis.de/proceedings/TIEP2013/05bouche.pdf, last accessed 2021/07/24.

44. Rakosnik, J., Stanchev, P., Simeonov, G., Pavlov, R.: Bulgarian Digital Mathematical Library BulDML and Czech Digital Mathematical Library DML-CZ as Parts of the European Digital Mathematics Library EuDML. In: 2nd Int. Conf. Digital Preservation and Presentation of Cultural Heritage. V. Tarnovo 2. P. 60-67 (2012).

45. Evstigneeva, G.A., Zemskov, A.I.: RusDML - A Russian-German Project for Establishing a Digital Archive of the Russian Mathematical Publications. Lecture Notes in Computer Science 2730. P. 44-51 (2003). https://doi.org/10.1007/978-3-540-45155-6_5

46. Elizarov, A.M., Lipachev, E.K.: Lobachevskii DML: Towards a Semantic Digital Mathematical Library of Kazan University. In: CEUR Workshop Proceedings 2022. P. 326-333 (2017). URL: http://ceur-ws.org/Vol-2022/paper50.pdf, last accessed 2021/07/24.

47. Elizarov, A.M., Lipachev, E.K.: Big Math Methods in Lobachevskii-DML Digital Library. In: CEUR Workshop Proceedings 2523. P. 59-72 (2019). URL: http://ceur-ws.org/Vol2523/invited08.pdf, last accessed 2021/07/24.

48. Gafurova, P.O., Elizarov, A.M., Lipachev, E.K.: Basic Services of Factory Metadata Digital Mathematical Library Lobachevskii-DML. Russian Digital Libraries Journal 23 (3). P. 336381 (2020). https://doi.org/10.26907/1562-5419-2020-23-3-336-381

49. Elizarov, A.M., Lipachev, E.K.: Digital Library Metadata Factories. In: CEUR Workshop Proceedings 2813. P. 13-21 (2021). URL: http://ceur-ws.org/Vol-2813/rpaper01.pdf, last accessed 2021/07/24.

50. D7.4: Toolset for Image and Text Processing and Metadata Enhancements - Final Release. URL: https://wiki.eudml.eu/mediawiki/eudml/images/D7.4-v1.0.pdf, last accessed 2021/07/24.

51. Journal Article Tag Suite. URL: https://jats.nlm.nih.gov/about.html, last accessed 2021/07/24. 
52. Elizarov, A.M, Khaydarov, Sh.M., Lipachev, E.K.: Scientific Documents Ontologies for Semantic Representation of Digital Libraries. In: Proceedings of the 2nd Russia and Pacific Conference on Computer Technology and Applications (RPC 2017). IEEE. P. 1-5 (2017). https://doi.org/10.1109/RPC.2017.8168064

53. Elizarov, A.M., Lipachev, E.K., Khaydarov, S.M.: Automated System of Services for Processing of Large Collections of Scientific Documents. In: CEUR Workshop Proceedings 1752. P. 58-64 (2016). URL: http://ceur-ws.org/Vol-1752/paper10.pdf, last accessed 2021/07/24.

54. Elizarov, A.M., Lipachev, E.K.: Methods of Processing Large Collections of Scientific Documents and the Formation of Digital Mathematical Library. In: CEUR Workshop Proceedings 2543. P. 354-360 (2020). URL: http://ceur-ws.org/Vol-2543/spaper05.pdf, last accessed 2021/07/24.

55. Elizarov, A.M., Zaitseva, N.V., Zuev, D.S., Lipachev, E.K., Khaidarov, S.M.: Services for Formation of Digital Documents Metadata in the Formats of International Science-based Databases. In: CEUR Workshop Proceedings 2260. P. 175-185 (2018). URL: http://ceurws.org/Vol-2260/53_175-185.pdf, last accessed 2021/07/24.

56. Gafurova, P.O., Elizarov, A.M., Lipachev, E.K., Khammatova, D.M.: Metadata Normalization Methods in the Digital Mathematical Library. In: CEUR Workshop Proceedings 2543. P. 136-148 (2020). URL: http://ceur-ws.org/Vol-2543/rpaper13.pdf, last accessed 2021/07/24.

57. Nilsson, M., Naeve, A., Duval, E., Johnston, P., Massart, D.: Harmonization Methodology for Metadata Models. URL: https://hal.archives-ouvertes.fr/hal-00591548, last accessed 2021/07/24.

58. Nilsson, M.: From Interoperability to Harmonization in Metadata Standardization, Doctoral thesis, Stockholm, Sweden (2010).

59. MacGregor, J., Stranack, K., Willinsky, J.: The Public Knowledge Project: Open Source Tools for Open Access to Scholarly Communication. In: S. Bartling, S. Friesike (Ed.): Opening Science. The Evolving Guide on How the Internet is Changing Research, Collaboration and Scholarly Publishing, Springer International Publishing. P. 165-175 (2014).

https://doi.org/10.1007/978-3-319-00026-8_3 